\title{
Management of Coincident Pituitary Macroadenoma and Cavernous Carotid Aneurysm: A Systematic Literature Review
}

\author{
Keenan J. Piper ${ }^{1}$ Michael Karsy ${ }^{2}$ Blair Barton ${ }^{3}$ Mindy Rabinowitz ${ }^{3}$ Marc R. Rosen ${ }^{3}$ \\ Gurston G. Nyquist ${ }^{3}$ James J. Evans ${ }^{2}$ Stavropoula Tjoumakaris ${ }^{2}$ Christopher J. Farrell ${ }^{2}$ \\ ${ }^{1}$ Sidney Kimmel Medical College, Thomas Jefferson University \\ Hospital, Philadelphia, Pennsylvania, United States \\ 2 Department of Neurological Surgery, Thomas Jefferson University \\ Hospital, Philadelphia, Pennsylvania, United States \\ ${ }^{3}$ Department of Otolaryngology, Thomas Jefferson University \\ Address for correspondence Christopher J. Farrell, MD, Department \\ of Neurological Surgery, Thomas Jefferson University Hospital, \\ Philadelphia 19107, PA, United States \\ (e-mail: christopher.farrell@jefferson.edu).
} Hospital, Philadelphia, Pennsylvania, United States

J Neurol Surg Rep 2021;82:e25-e31.

\begin{abstract}
Introduction Pituitary adenomas are a common intracranial pathology with an incidence of 15 to $20 \%$ in the population while cerebral aneurysms are less common with a prevalence of $1: 50$ patients. The incidence of aneurysms in patients with pituitary adenoma has been estimated at 2.3 to $5.4 \%$ of patients; however, this remains unclear. Equally, the management of concomitant lesions lacks significant understanding.

Methods A case report is presented of a concomitant cerebral aneurysm and pituitary adenoma managed by minimally invasive endovascular and endoscopic methods, respectively. A systematic review of the literature for terms "pituitary adenoma" and

Keywords

- macroadenoma

- cavernous carotid aneurysm

- pipeline

- endoscopic

- transphenoidal

- pituitary adenoma

- intracranial aneurysm

"aneurysm" yielded 494 studies that were narrowed to 19 relevant articles.

Results We report a case of a 67-year-old patient with an enlarging pituitary macroadenoma, cavernous carotid aneurysm, and unilateral carotid occlusion. After successful treatment of the aneurysm by a pipeline flow diverter, the pituitary adenoma was surgically resected by an endoscopic transsphenoidal approach.

Conclusion The use of a pipeline flow diverter and endonasal approach was feasible in the treatment of our patient. This is the first report to our knowledge of the use of pipeline flow diversion in the management of a cavernous carotid aneurysm prior to pituitary adenoma treatment.
\end{abstract}

\section{Introduction}

Pituitary adenomas are the third most common intracranial tumors in adults with an estimated prevalence of approximately 15 to $20 \%$ of the population. ${ }^{1}$ Although pituitary adenomas are overwhelmingly benign, they can still confer significant health burden due to visual loss and endocrine dysfunction. Management of pituitary adenomas remains complex due to the heterogeneity of tumor types with multiple guidelines and consensus statements currently received

November 8, 2020

accepted after revision

May 26, 2021
DOI https://doi.org/

$10.1055 / \mathrm{s}-0041-1735904$.

ISSN 2193-6358.

\footnotetext{
(C) 2021. The Author(s).

This is an open access article published by Thieme under the terms of the Creative Commons Attribution-NonDerivative-NonCommercial-License, permitting copying and reproduction so long as the original work is given appropriate credit. Contents may not be used for commercial purposes, or adapted, remixed, transformed or built upon. (https://creativecommons.org/ licenses/by-nc-nd/4.0/) Georg Thieme Verlag KG, Rüdigerstraße 14, 70469 Stuttgart, Germany
} 
being available; however, surgical resection remains the mainstay of treatment for the majority of symptomatic pituitary adenomas. $^{2-4}$

Intracerebral aneurysms show a prevalence of 1:50 for unruptured aneurysms; however, the presence of coincident pituitary adenomas and cerebral aneurysms is rare. ${ }^{5}$ Retrospective studies demonstrate an incidence of intracranial aneurysm in patients with a pituitary adenoma of 2.3 to $5.4 \%,{ }^{6,7}$ suggesting a purely coincidental relationship.

The combination of a cavernous sinus aneurysm embedded within a pituitary adenoma is even rarer and the approach for treatment is controversial. In this report, we detail the management of a patient with a nonfunctioning pituitary macroadenoma and an embedded cavernous carotid aneurysm. A systematic review of the literature was performed showing 20 prior reports of pituitary adenomas with associated aneurysms of the cavernous sinus (-Table 1). We also discuss the integration of modern endovascular therapy and propose a novel treatment strategy.

\section{Literature Review}

A systematic literature review was performed on PubMed with search terms "pituitary adenoma" and "aneurysm." A total of 494 studies were identified and after review of study titles and abstracts, the number was narrowed down to 20 articles after removing duplicates, studies not in English, and nonclinical studies (-Fig. 1). Patients were included if they demonstrated concomitantly treated pituitary adenomas and intracerebral aneurysms of the cavernous sinus. The Preferred Reporting Items for Systematic Reviews and MetaAnalyses (PRISMA) guidelines were used in drafting this manuscript.

\section{Case Report}

The patient was an asymptomatic 67-year-old male presenting with a nonfunctional pituitary macroadenoma $(17 \mathrm{~mm}$ $\times 16 \mathrm{~mm} \times 13 \mathrm{~mm}$ ) and an associated left cavernous carotid artery aneurysm protruding into the left superior aspect of the tumor discovered incidentally during evaluation for headaches (-Fig. 2). The pituitary adenoma showed superior displacement of the normal pituitary gland and minimal suprasellar extension without abutment of the optic chiasm. Vascular imaging showed a left cavernous carotid artery aneurysm $(3.7 \mathrm{~mm} \times 3.4 \mathrm{~mm})$, complete right internal carotid artery (ICA) occlusion, and a small anterior communicating artery (ACOM) aneurysm.

The macroadenoma and aneurysm were followed closely with serial imaging for 6 years until slow progressive growth of the pituitary adenoma demonstrated compression of the optic chiasm. Ophthalmologic evaluation revealed no visual deficits. After a multidisciplinary discussion, a recommendation for initial repair of the aneurysm followed by delayed tumor treatment was made. The patient proceeded initially with attempted coil embolization which could not be completed due to aneurysm anatomy. Subsequently, a
$5 \mathrm{~mm} \times 18 \mathrm{~mm}$ pipeline flex flow diverter was placed. The patient was maintained on dual antiplatelet therapy and the aneurysm showed complete radiographic occlusion 6 months later (-Fig. 3). Repeat magnetic resonance (MR) imaging showed progression of the macroadenoma $(21 \mathrm{~mm}$ $\times 19 \mathrm{~mm} \times 22 \mathrm{~mm}$ ) with increasing optic tract compression. Unfortunately, before tumor surgery could be performed, the patient suffered a minor cerebrovascular accident (CVA) which was treated with resumption of dual antiplatelet treatment for an additional 6 months and continued on maintenance aspirin.

For the pituitary adenoma resection, an endoscopic transsphenoidal approach was performed using the previously described "1.5 approach" that involves a full unilateral sphenoidotomy and smaller contralateral sphenoidotomy with preservation of bilateral sphenopalatine artery pedicles to the nasal septum. ${ }^{8}$ During surgery, extreme caution was taken in the left lateral region of the sella where the aneurysm and only patent carotid artery were located. A gross total resection of the tumor was accomplished. The patient was discharged on postoperative day 1 and aspirin was reinitiated 3 days postsurgery without complication.

\section{Discussion}

The presence of a pituitary macroadenoma with an embedded cavernous sinus aneurysm is an exceptionally rare phenomenon which requires special considerations. ${ }^{6,9}$ Currently available guidelines ${ }^{2-4}$ do not make specific recommendations on this rare situation. The incorporation of endovascular treatments in the management of pituitary tumors and aneurysms has had limited exploration.

We conducted a review of the literature and analyzed all case reports discussing the phenomenon of a cavernous sinus aneurysm embedded within a pituitary adenoma (-Fig. 1). A total of 20 studies described pituitary adenomas in direct contact with cavernous sinus aneurysms ( - Table $\mathbf{1}$ ). Regarding aneurysm treatment among the 20 studies, 14 involved endovascular approaches, 5 involved open approaches, and 1 case showed a patient fatality prior to treatment. For adenoma treatment, 4 involved transcranial approaches, 11 involved endonasal approaches, 4 involved medical management, and 1 patient had a fatality prior to

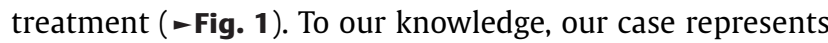
the first case of initial aneurysm treatment with pipeline flow diversion prior to adenoma treatment. The use of the pipeline aided the treatment of an aneurysm in an otherwise difficult location to treat. Certainly, the use of a pipeline stent and need for antiplatelet medication complicate the timing for adenoma resection; however, as most adenomas are slow growing, the urgency of tumor treatment is less significant.

Several cases of ruptured intracranial carotid artery aneurysms embedded within adenomas causing subarachnoid hemorrhage have been reported. ${ }^{10}$ Additionally, aneurysms in the posterior circulation have also been described which may confer increased surgical morbidity during pituitary surgery. ${ }^{11}$ Cavernous carotid artery aneurysms located proximal to the distal dural ring present a decreased risk for 


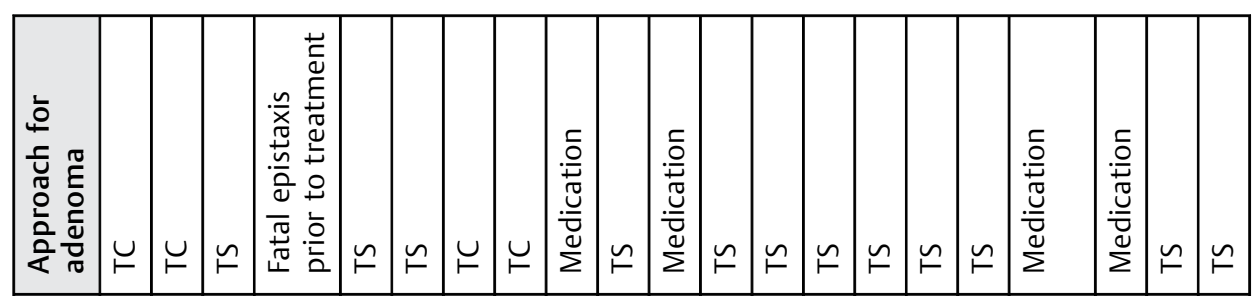

\section{(1)}

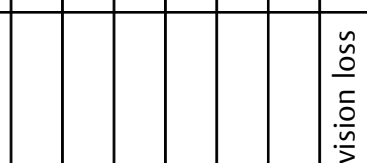

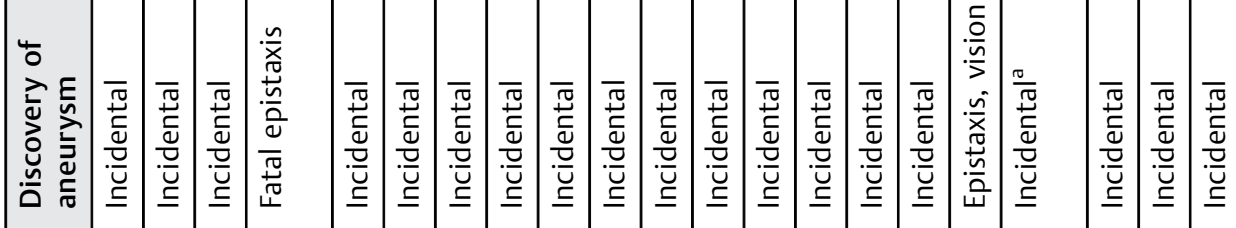

\begin{tabular}{|c|c|c|c|c|c|c|c|c|c|c|c|c|c|c|c|c|c|c|c|c|c|}
\hline 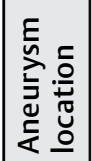 & $\underline{\Xi}$ & $\underline{\mathbb{}}$ & $\frac{\mathbb{U}}{\tilde{U}}$ & $\frac{\mathbb{J}}{\tilde{U}}$ & $\underline{\mathbb{\mho}}$ & $\bar{y}$ & $\frac{\mathbb{U}}{\tilde{U}}$ & $\frac{\mathbb{U}}{\tilde{U}}$ & $\frac{\mathbb{J}}{\tilde{U}}$ & $\underline{\Xi}$ & $\frac{\overleftarrow{\Xi}}{\tilde{U}}$ & $\underline{\mathbb{E}}$ & $\underline{\mathbb{U}}$ & 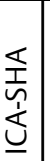 & 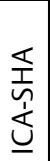 & $\begin{array}{l}\underline{x} \\
\underline{\hat{n}} \\
\underline{\dot{u}} \\
\underline{4}\end{array}$ & $\frac{\mathbb{\Xi}}{\tilde{U}}$ & $\frac{\mathbb{U}}{\tilde{U}}$ & $\underline{\mathbb{\Xi}}$ & 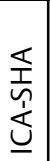 & $\frac{\mathbb{\Xi}}{\tilde{U}}$ \\
\hline
\end{tabular}




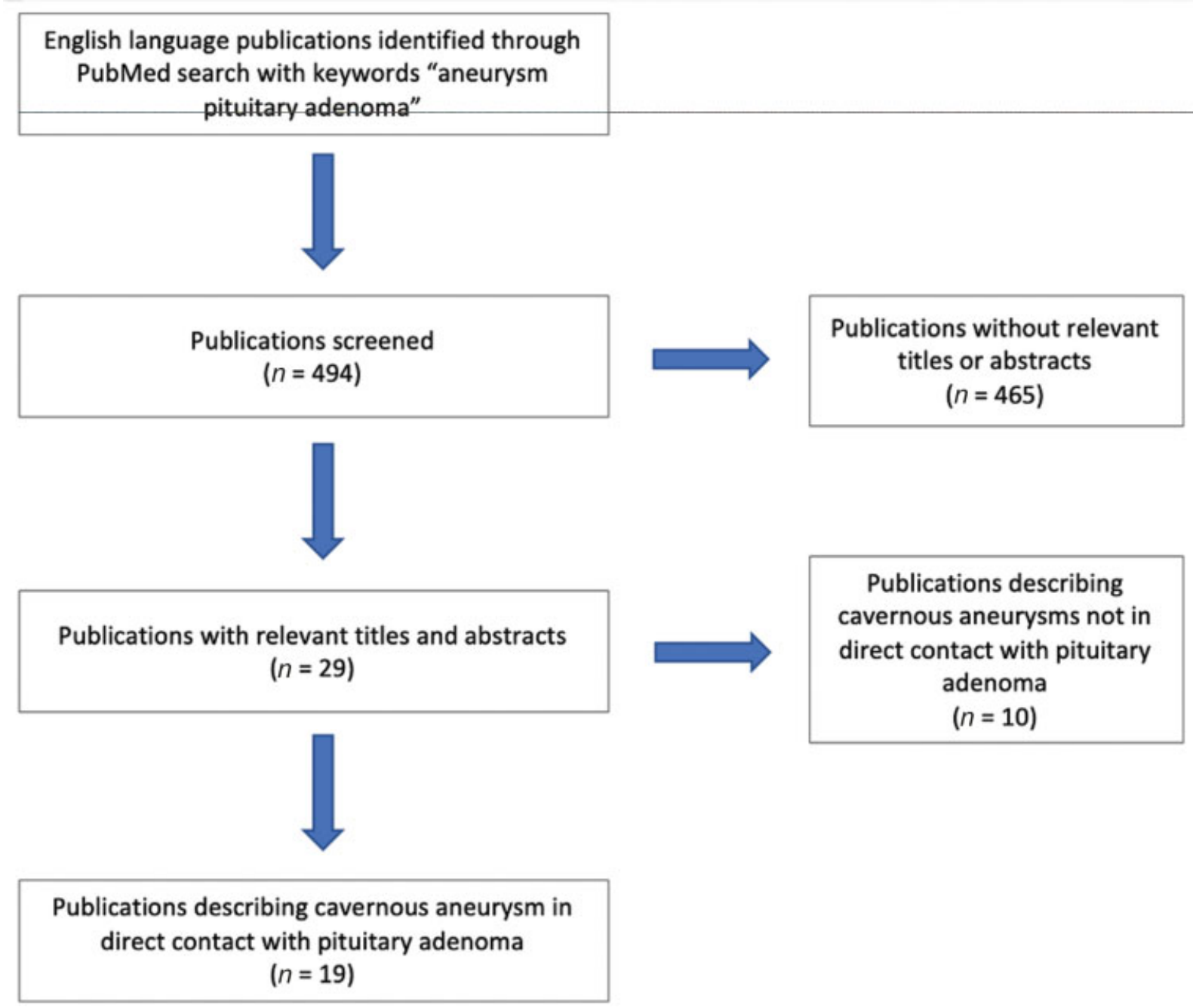

Fig. 1 PRISMA flowchart describing the methods of literature review in this study. PRISMA, The Preferred Reporting Items for Systematic Reviews and Meta-Analyses.

rupture-associated morbidity and mortality due to their extradural origin and are therefore less commonly treated surgically or endovascularly. ${ }^{5}$ Rupture of aneurysms extending within pituitary adenomas, however, may present as pituitary apoplexy with visual, cranial nerve, and endocrine dysfunction. ${ }^{12}$ Additionally, cavernous aneurysms located within pituitary adenomas carry risk for catastrophic rupture during surgical resection of these tumors. While the mortality rate for aneurysm rupture during pituitary surgery is not known, a $14 \%$ mortality rate after carotid artery injury during transsphenoidal surgery has been reported with a $24 \%$ rate of significant neurological disability. ${ }^{13}$ As such, the decision to proceed with surgical intervention for pituitary adenomas in these rare cases requires either a preoperative or concomitant strategy for treating the aneurysm.

Fortunately, management strategies for the treatment of cerebral aneurysms have greatly expanded and improved over the last several decades with the decision to coil, flowdivert, or clip a cerebral aneurysm partially depending on the angiographic features of the aneurysm and ability to tolerate single or dual antiplatelet agents to prevent thromboembolic complications. Several cases of simultaneous open transcranial or combined transcranial and endoscopic clip ligation management of intracranial aneurysm rupture and pituitary adenoma resection have been reported in the setting of subarachnoid hemorrhage. ${ }^{14}$ Although open surgical treatment of a carotid cavernous aneurysm and pituitary adenoma has been described previously in the literature, ${ }^{15,16}$ this method has been replaced by modern endovascular techniques. Endovascular treatments are generally associated with lower medical comorbidity than open treatment but may require the use of single or dual antiplatelet agents that would delay the timing of pituitary adenoma treatment, especially with the use of flow diversion. ${ }^{17}$

Modern approaches for the treatment of pituitary adenomas and carotid aneurysms have incorporated the use of endovascular treatment to secure aneurysms before tumor surgery. ${ }^{18}$ Coil embolization typically does not require the postoperative use of antiplatelet agents and may be considered the preferred option for securing the aneurysm. Endovascular coiling, however, is highly dependent on the aneurysm morphology and may result in incomplete aneurysm obliteration or aneurysm recurrence. Alternatively, for aneurysms with wide necks or not amenable to direct 


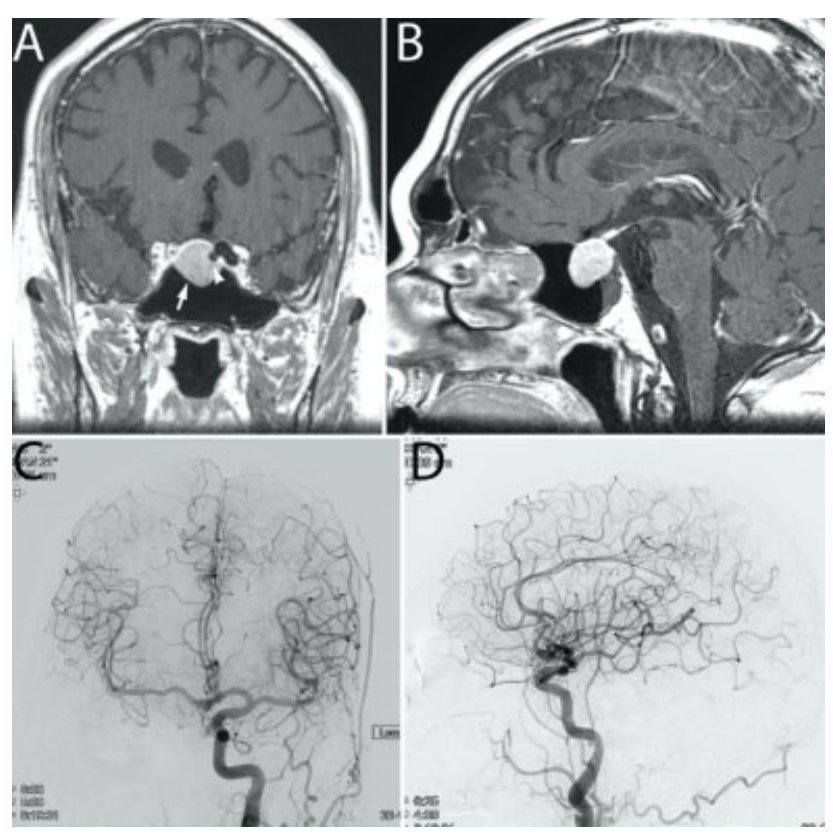

Fig. 2 Preoperative MRI and angiogram views of concomitant pituitary adenoma and internal carotid artery aneurysm. Preoperative (A) coronal and (B) sagittal T1 contrast enhanced imaging demonstrates a pituitary macroadenoma with expansion of the sella (arrow). The left sided cavernous segment aneurysm can be noted as a flow void (arrowhead). (C) Anteroposterior and (D) lateral cerebral angiogram views demonstrate a medial projecting cavernous segment aneurysm.

coiling, stent-assisted coiling or flow-diversion strategies may be utilized. Flow diverters promote aneurysm occlusion through a process of endoluminal reconstruction of the parent artery and by redirecting blood flow away from the aneurysm sac. Review of patients at our institution treated with the pipeline embolization device demonstrated a complete aneurysm occlusion rate of $86 \%$ which was significantly higher than that achieved with coiling $(41 \%) .{ }^{19}$ The thrombogenicity of flow diversion stents, however, requires the use of single- or dual-antiplatelet therapy to reduce the risks of thromboembolic complications. Overall, thromboembolic events have been observed in approximately $6 \%$ of patients with higher rates of complications occurring in patients treated with aspirin and clopidogrel therapy for less than 6 months. ${ }^{20}$ Therefore, the use of aneurysm obliteration via flow diversion should occur at least 6 months prior to any planned surgical intervention for the pituitary adenoma and may be best reserved for asymptomatic patients without optic apparatus compression or progressively enlarging adenomas where intervention may be safely delayed.

Many cavernous sinus aneurysms do not present with symptoms, though some may result in cranial nerve palsies due to their proximity in the cavernous sinus. According to Stiebel-Kalish et al, the most common presenting symptoms are diplopia (65\%), pain (59\%), and unilateral headaches (33\%). ${ }^{21}$ Less commonly, the aneurysms may rupture, causing carotid-cavernous fistulas or severe epistaxis warranting immediate surgical intervention. In 18 of the 20 cases included in our systematic review, the cavernous aneurysms were found incidentally on imaging workup ( - Table 1 ) and

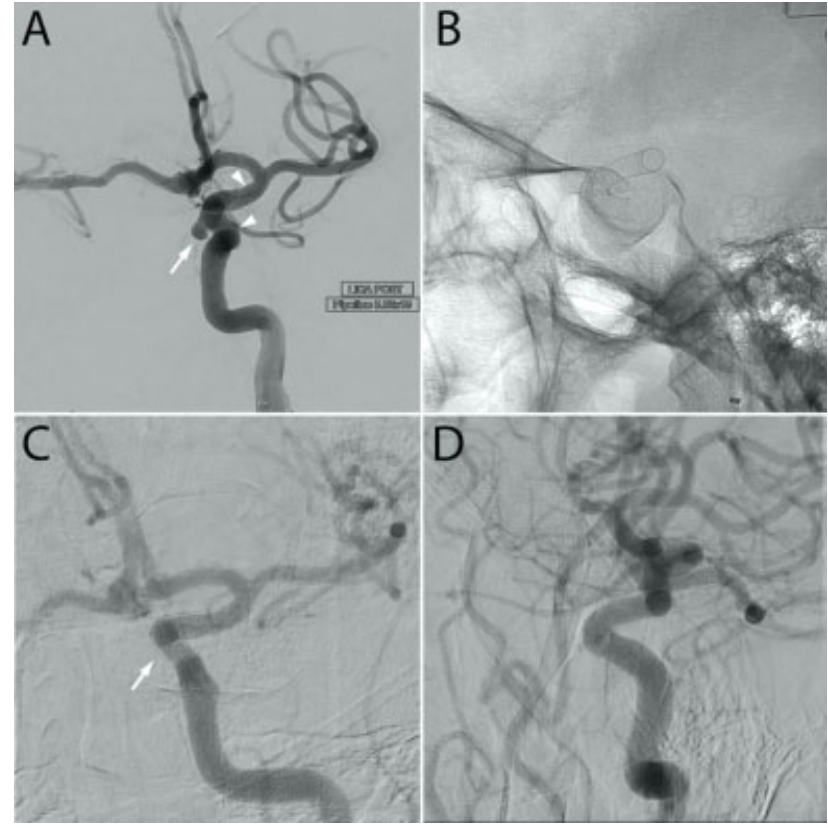

Fig. 3 Diagnostic cerebral angiogram demonstrating complete occlusion of a medial internal carotid artery aneurysm. (A) Anteroposterior and (B) lateral cerebral angiogram views demonstrates a medially projection cavernous segment (arrow) along with the limits of a Pipeline flow diverter (arrowhead). 6-month followup (C) anteroposterior and (D) lateral cerebral angiogram views demonstrate resolution of the aneurysm (arrow).

the selection of treatment for these incidental aneurysms will depend on patient risk factors, aneurysm morphology, and tumor behavior including the urgency with which the adenoma must be treated.

In general, the preferred treatment for ruptured or unruptured cavernous aneurysm with a pituitary adenoma would be endovascular coiling. Antiplatelet therapy is generally not required and this intervention has been shown to provide aneurysm protection with low morbidity and facilitate transsphenoidal resection of the adenoma. ${ }^{10,18,22-26}$ The rare cases of aneurysms are not amenable to coiling for which urgent decompression of the adenoma is necessary, typically due to macroadenomas with suprasellar extension and vision loss or pituitary apoplexy, a transcranial approach with simultaneous tumor resection and clipping of the aneurysm may be indicated. ${ }^{15,16,27,28}$ While endoscopic endonasal intracranial clipping of cavernous carotid aneurysm has been reported and is technically feasible, simultaneous endonasal pituitary adenoma resection and aneurysm has not been performed to the best of our knowledge. ${ }^{29}$ Additionally, a recent review of endonasal aneurysm clipping demonstrated significantly higher rates of complications compared with open clipping and endovascular management. ${ }^{30}$ In our opinion, consideration of endoscopic endonasal clipping of an aneurysm during pituitary adenoma resection is best reserved for emergency management of inadvertent intraoperative aneurysmal rupture encountered during the tumor resection. In the event that an unruptured aneurysm is unexpectedly discovered during pituitary adenoma resection, due to the potential for catastrophic 
hemorrhagic complications, we recommend that subtotal tumor resection to be performed without perturbation of the aneurysm. Subsequent definitive aneurysm therapy may then be pursued followed by delayed reintervention for the adenoma if clinically indicated.

As an additional point of consideration, surgical reconstruction of the skull base defect after adenoma resection by use of a nasoseptal flap may warranted to provide long-term protection of the aneurysm from inadvertent injury from subsequent interventions, such as nasogastric tube placement or to provide an additional layer of coverage, to the aneurysm wall in cases of stereotactic radiosurgery is anticipated. $^{30,31}$

\section{Conclusion}

This case report and systematic review suggests that concomitant treatment of cerebral aneurysms and pituitary adenomas requires knowledge of up-to-date surgical and endovascular options for each pathology, as well as careful consideration of the timing and sequence of intervention.

\section{Ethics Statement}

Michael Karsy reports disclosure with Cyrus Surgical (part owner) and Thieme Medical Publishing (royalties).

\section{Funding}

Publication made possible in part by support from the Thomas Jefferson University Open Access Fund.

\section{Conflict of Interest}

None declared.

\section{References}

1 Ezzat S, Asa SL, Couldwell WT, et al. The prevalence of pituitary adenomas: a systematic review. Cancer 2004;101(03):613-619

2 Freda PU, Beckers AM, Katznelson L, et al; Endocrine Society. Pituitary incidentaloma: an endocrine society clinical practice guideline. J Clin Endocrinol Metab 2011;96(04):894-904

3 Aghi MK, Chen CC, Fleseriu M, et al. Congress of neurological surgeons systematic review and evidence-based guidelines on the management of patients with nonfunctioning pituitary adenomas: executive summary. Neurosurgery 2016;79(04):521-523

4 Chanson P, Raverot G, Castinetti F, Cortet-Rudelli C, Galland F, Salenave SFrench Endocrinology Society non-functioning pituitary adenoma work-group. Management of clinically non-functioning pituitary adenoma. Ann Endocrinol (Paris) 2015;76(03): 239-247

5 Seinfeld J, Karim S. Cavernous sinus aneurysm. In: StatPearls. StatPearls PublishingTreasure Island, FL2020

6 Oh MC, Kim EH, Kim SH. Coexistence of intracranial aneurysm in 800 patients with surgically confirmed pituitary adenoma. J Neurosurg 2012;116(05):942-947

7 Pant B, Arita K, Kurisu K, Tominaga A, Eguchi K, Uozumi T. Incidence of intracranial aneurysm associated with pituitary adenoma. Neurosurg Rev 1997;20(01):13-17

8 Farrell CJ, Nyquist GG, Farag AA, Rosen MR, Evans JJ. Principles of pituitary surgery. Otolaryngol Clin North Am 2016;49(01): 95-106

9 Hanak BW, Zada G, Nayar VV, et al. Cerebral aneurysms with intrasellar extension: a systematic review of clinical, anatomical, and treatment characteristics. J Neurosurg 2012;116(01): 164-178

10 Choi HS, Kim MS, Jung YJ, Kim OL. Incidental superior hypophygeal artery aneurysm embedded within pituitary adenoma. J Korean Neurosurg Soc 2013;54(03):250-252

11 Habibi Z, Miri SM, Sheikhrezaei A. Pituitary macroadenoma coexistent with a posterior circulation aneurysm leading to subarachnoidal hemorrhage during transsphenoidal surgery. Turk Neurosurg 2015;25(03):469-474

12 Peng $Z$, Tian $D$, Wang $H$, et al. Epistaxis and pituitary apoplexy due to ruptured internal carotid artery aneurysm embedded within pituitary adenoma. Int J Clin Exp Pathol 2015;8(11):14189-14197

13 Raymond J, Hardy J, Czepko R, Roy D. Arterial injuries in transsphenoidal surgery for pituitary adenoma; the role of angiography and endovascular treatment. AJNR Am J Neuroradiol 1997;18 (04):655-665

$14 \mathrm{Kino} \mathrm{H}$, Ito Y, Akutsu $\mathrm{H}$, et al. Combined endoscopic endonasal and bilateral subfrontal approach for a nonfunctioning pituitary adenoma associated with an internal carotid artery-superior hypophyseal artery aneurysm. World Neurosurg 2020; 134:297-301

15 Hori T, Muraoka K, Hokama Y, Takami M, Saito Y. A growthhormone-producing pituitary adenoma and an internal carotid artery aneurysm. Surg Neurol 1982;18(02):108-111

16 Matsuyama T, Masuda A. A rare case of infraclinoid aneurysm accompanied with pituitary adenoma extending over the extrasellar space [in Japanese]. No Shinkei Geka 1993;21(02):171-175

17 Molyneux A, Kerr R, Stratton I, et al; International Subarachnoid Aneurysm Trial (ISAT) Collaborative Group. International Subarachnoid Aneurysm Trial (ISAT) of neurosurgical clipping versus endovascular coiling in 2143 patients with ruptured intracranial aneurysms: a randomised trial. Lancet 2002;360(9342): 1267-1274

18 Yamada S, Yamada SM, Hirohata T, et al. Endoscopic extracapsular removal of pituitary adenoma: the importance of pretreatment of an adjacent unruptured internal carotid artery aneurysm. Case Rep Neurol Med 2012;2012:891847

19 Chalouhi N, Tjoumakaris S, Starke RM, et al. Comparison of flow diversion and coiling in large unruptured intracranial saccular aneurysms. Stroke 2013;44(08):2150-2154

20 Saber H, Kherallah RY, Hadied MO, Kazemlou S, Chamiraju P, Narayanan S. Antiplatelet therapy and the risk of ischemic and hemorrhagic complications associated with pipeline embolization of cerebral aneurysms: a systematic review and pooled analysis. J Neurointerv Surg 2019;11(04):362-366

21 Stiebel-Kalish H, Kalish Y, Bar-On RH, et al. Presentation, natural history, and management of carotid cavernous aneurysms. Neurosurgery 2005;57(05):850-857, discussion 850-857

22 Salpietro FM, Longo M, Alafaci C, Gervasio O, Tomasello F. Coexisting pituitary tumour and intracavernous asymptomatic aneurysm: management implications. Acta Neurochir (Wien) 1997;139(08):791-792

23 Sade B, Mohr G, Tampieri D, Rizzo A. Intrasellar aneurysm and a growth hormone-secreting pituitary macroadenoma. Case report. J Neurosurg 2004;100(03):557-559

24 Wang CS, Yeh TC, Wu TC, Yeh CH. Pituitary macroadenoma coexistent with supraclinoid internal carotid artery cerebral aneurysm: a case report and review of the literature. Cases J 2009;2:6459

25 Yu K, Herwadkar A, Kearney T, Gnanalingham KK. Pituitary adenoma and incidental superior hypophyseal aneurysm. $\mathrm{Br} \mathrm{J}$ Neurosurg 2011;25(03):432-433

26 Xia X, Ramanathan M, Orr BA, et al. Expanded endonasal endoscopic approach for resection of a growth hormone-secreting pituitary macroadenoma coexistent with a cavernous carotid artery aneurysm. J Clin Neurosci 2012;19(10):1437-1441

27 Yang MY, Chen C, Shen CC. Cavernous aneurysm and pituitary adenoma: management of dual intrasellar lesions. J Clin Neurosci 2005;12(04):477-481 
28 Chuang CC, Chen YL, Pai PC. A giant intracavernous carotid artery aneurysm embedded in pituitary macroadenoma presenting with pituitary apoplexy. Cerebrovasc Dis 2006;21(1,2):142-144

29 Xiao LM, Tang B, Xie SH, et al. Endoscopic endonasal clipping of anterior circulation aneurysm: surgical techniques and results. World Neurosurg 2018;115:e33-e44

30 Martinez-Perez R, Hardesty DA, Silveira-Bertazzo G, AlbonetteFelicio T, Carrau RL, Prevedello DM. Safety and effectiveness of endoscopic endonasal intracranial aneurysm clipping: a systematic review. Neurosurg Rev 2021;44(02):889-896

31 Ryu G, So YK, Seo MY, et al. Using the nasoseptal flap for reconstruction after endoscopic debridement of radionecrosis in nasopharyngeal carcinoma. Am J Rhinol Allergy 2018;32(01):61-65

32 Imamura J, Okuzono T, Okuzono Y. Fatal epistaxis caused by rupture of an intratumoral aneurysm enclosed by a large prolactinoma-case report. Neurol Med Chir (Tokyo) 1998;38(10): 654-656

33 Ohki M, Sato K, Tuchiya D, et al. A case of TSH-secreting pituitary adenoma associated with an unruptured aneurysm: successful treatment by two-stage operation and gamma-knife [in Japanese]. No To Shinkei 1999;51(10):895-899
34 Curto L, Squadrito S, Almoto B, et al. MRI finding of simultaneous coexistence of growth hormone-secreting pituitary adenoma with intracranial meningioma and carotid artery aneurysms: report of a case. Pituitary 2007;10(03):299-305

35 Seda L Jr., Cukiert A, Nogueira KC, Huayllas MK, Liberman B. Intrasellar internal carotid aneurysm coexisting with $\mathrm{GH}$-secreting pituitary adenoma in an acromegalic patient. Arq Neuropsiquiatr 2008;66(01):99-100

36 Soni A, De Silva SR, Allen K, Byrne JV, Cudlip S, Wass JA. A case of macroprolactinoma encasing an internal carotid artery aneurysm, presenting as pituitary apoplexy. Pituitary 2008;11(03): 307-311

37 Khalsa SS, Hollon TC, Shastri R, Trobe JD, Gemmete JJ, Pandey AS. Spontaneous subarachnoid hemorrhage due to ruptured cavernous internal carotid artery aneurysm after medical prolactinoma treatment. BMJ Case Rep 2016;2016:2016

38 Khachatryan T, Khachatryan M, Fanarjyan R, Grigoryan M, Grigorian A. Enlargement of an incidental internal carotid artery aneurysm embedded in pituitary adenoma associated with medical shrinkage of the tumor: Case report. Surg Neurol Int 2018; 9:30 